\title{
Revista
}

\section{SE REAVIVA EL DEBATE SOBRE LA PRESCRIPCIÓN DE LA ACCIÓN DE RESTITUCIÓN DE LOS GASTOS HIPOTECARIOS TRAS LA NOTA INFORMATIVA DEL MINISTERIO DE CONSUMO DE 17.11.2020*}

\author{
Sheila Martínez Gómez \\ Centro de Estudios de Consumo \\ Universidad de Castilla-La Mancha
}

\begin{abstract}
Resumen: Este trabajo realiza un análisis de las diferentes líneas jurisprudenciales existentes sobre la prescripción de la acción restitutoria derivada de la acción de nulidad absoluta de la cláusula de gastos, así como un análisis crítico de la nota informativa del Ministerio de Consumo que sitúa el inicio del cómputo del plazo de prescripción desde la publicación de la STS de 23 de diciembre de 2015.
\end{abstract}

Palabras Clave: Cláusulas abusivas, préstamo hipotecario, cláusula de gastos, acción restitutoria, prescripción, cómputo del plazo.

Abstract: This paper analyzes the different jurisprudential lines on the prescription of the restitution action derived from the nullity action of the expenses terms. Additionally, it carries out a critical analysis of the informative note of the Spanish Ministry Consumer Affairs that determines initial date of limitation period since the publication of the Spanish Supreme Court judgment of 23 December 2015.

Key words: Unfair terms, mortgage loan, expenses terms, restitution action, prescription, calculation of initial date.

Sumario: I. Antecedentes. II. Las diferentes tesis existentes en la jurisprudencia respecto a la prescripción de la acción restitutoria. 1. Régimen de prescripción aplicable: ¿art. 1303 o art. 1964.2 CC? 1.1. Tesis sobre la imprescriptibilidad. 1.2.

\footnotetext{
* Trabajo realizado en el marco del Contrato con referencia 2020-COB-9855 financiado con la Ayuda para la financiación de actividades de investigación dirigidas a grupos de la UCLM Ref.: 2019-GRIN-27198, denominado "Grupo de Investigación del Profesor Ángel Carrasco" (GIPAC) y en el marco del Proyecto de Investigación PGC2018-098683-B-I00, del Ministerio de Ciencia, Innovación y Universidades (MCIU) y la Agencia Estatal de Investigación (AEI) cofinanciado por el Fondo Europeo de Desarrollo Regional (FEDER) titulado "Protección de consumidores y riesgo de exclusión social" dirigido por Ángel Carrasco Perera y Encarna Cordero Lobato y en el marco de la ayuda para la realización de proyectos de investigación científica y transferencia de tecnología, de la Junta de Comunidades de Castilla-La Mancha cofinanciadas por el Fondo Europeo de Desarrollo Regional (FEDER) para el Proyecto titulado "Protección de consumidores y riesgo de exclusión social en Castilla-La Mancha" (PCRECLM) con Ref.: SBPLY/19/180501/000333 dirigido por Ángel Carrasco Perera y Ana Isabel Mendoza Losana.
} 
Se reaviva el debate sobre la prescripción de la acción de restitución de los gastos hipotecarios tras la nota informativa del Ministerio de

Tesis sobre la aplicación del plazo prescriptivo quinquenal del art. 1964.2 CC. 2. Dies a quo para el cómputo del plazo de prescripción de la acción restitutoria. 2.1. Tesis que fija el dies a quo en el momento que se hicieron efectivos los pagos. 2.2. Tesis que vincula el dies a quo con la publicación de la STS de 23 de diciembre de 2015. 2.3. Tesis que retrasa el dies a quo al momento en el que se declare judicialmente la nulidad de la cláusula. III. Crítica a la nota informativa del Ministerio de Consumo. IV. Bibliografía.

El pasado 5 de diciembre, el Ministerio de Consumo publicó una nota informativa sobre los derechos que asisten a las personas consumidoras en relación con los gastos derivados de las hipotecas ${ }^{1}$ en la que fija el dies a quo del cómputo del plazo de prescripción, para reclamar las cantidades abonadas por el consumidor en virtud de la cláusula de gastos, en el momento en el que se publicó la STS de 23 de diciembre de 2015 (el 21 de enero de 2016), generando un enorme revuelo en el sector jurídico y, por tanto, abriendo de nuevo el debate sobre la prescripción de la acción restitutoria de los gastos hipotecarios.

\section{Antecedentes}

Desde que el Alto Tribunal se pronunciara en la sentencia de 23 de diciembre de $2015^{2}$ sobre la validez de la cláusula de gastos de los préstamos hipotecarios, declarando nula y abusiva la repercusión al prestatario del pago del IAJD y de los gastos derivados de Notaría y Registro, muchas de las cuestiones controvertidas que se generaron en torno a esta cláusula han sido, en gran medida, resueltas (¿qué gastos son abusivos?; ¿puede instar el prestatario la nulidad de la cláusula aun cuando el préstamo se haya extinguido?; ¿el prestatario puede recuperar la totalidad o únicamente parte de los gastos abonados?; ¿puede oponer la entidad bancaria la excepción de enriquecimiento sin causa?).

Sin embargo, sigue sin haberse resuelto una de las cuestiones más controvertidas y debatidas en el ámbito de la cláusula de gastos: la prescripción de la acción de restitución anudada a la declaración de nulidad de la cláusula abusiva. El origen de este problema estriba en que no existe previsión alguna respecto a la determinación del plazo de prescripción aplicable a ese tipo de acción en la Directiva 93/13/CE ni tampoco en el TRLGDCU y ni en la LCGC $^{3}$, lo que conlleva la aplicación de las normas previstas en el propio Código civil.

Ha sido la remisión a este texto normativo lo que ha provocado posiciones doctrinales encontradas y una doctrina nada pacífica en nuestro Tribunales respecto a la imprescriptibilidad o no de la acción de restitución y a la determinación del dies a quo

\footnotetext{
${ }^{1}$ https://www.mscbs.gob.es/consumo/pec/docs/preguntasFrecuentesGastosHipotecarios.pdf

2 STS (Sala Primera, Sección Pleno) núm. 705/2015, de 23 de diciembre (RJ 2015\5714).

3 La LCGC sí determina, en su art. 19, que las acciones colectivas de cesación y retractación son, con carácter general, imprescriptibles.
} 
del cómputo del plazo prescriptivo. En concreto, nuestros juzgados y tribunales manejan, a día de hoy, cinco tesis o criterios diferentes en torno a la prescripción de la acción de restitución de los gastos hipotecarios.

\section{Las diferentes tesis existentes en la jurisprudencia respecto a la prescripción de la acción restitutoria}

\section{Régimen de prescripción aplicable: ¿art. 1303 o art. 1964.2 CC?}

No se cuestiona que la acción de nulidad de las cláusulas abusivas, en tanto nulidad absoluta o de pleno derecho (arts. 83 TRLGDCU y 10 bis LCGC), no está sujeta a plazo de prescripción pues la sentencia judicial se limita a constatar y declarar la ineficacia ex lege del acto nulo.

Lo que suscita controversias en la práctica judicial es si la prescripción se predica o no de la acción de reclamación o restitución de los gastos, es decir, si es posible establecer la reclamación de tales gastos como una consecuencia directa de la acción de nulidad ex art. 1303 CC o, por el contrario, se trata de una acción independiente que tiene su propio régimen jurídico y, por tanto, su propio plazo de prescripción.

\subsection{Tesis sobre la imprescriptibilidad}

Aunque la jurisprudencia se inclina por limitar la imprescriptibilidad a la declaración de nulidad en strictu sensu, algunas resoluciones judiciales ${ }^{4}$ sostienen que la remoción de las consecuencias jurídicas que puedan derivarse de la declaración de nulidad radical de una cláusula abusiva gozan de la misma imprescriptibilidad que la acción principal de nulidad.

Y esto porque «... no existe una acción independiente para solicitar las consecuencias jurídico-económicas que se puedan derivar de la nulidad de la cláusula; se trata de un mero efecto jurídico, por lo que la imprescriptibilidad de la acción para pedir la declaración de nulidad extiende su régimen jurídico a sus consecuencias... » [SAP de León (Sección $1^{\text {a }}$ ) núm. 378/2018 de 15 octubre5]. Además, «... es sabido por abundante doctrina jurisprudencial, que la restitución a la que se refiere el art. $1303 \mathrm{CC}$ es un efecto ex lege, esto es, no nace del contrato anulado, sino de la ley (SSTS de 24-10-1989, 24-2-1992, 23-6-2008). Se trata de consecuencia natural e ineludible que va necesariamente vinculada a la nulidad (STS de 8-1-2007) (...), pues tiene como teología el conseguir que las

\footnotetext{
${ }^{4}$ Sentencias de las AAPP de Alicante (Sección Tribunal de Marca Comunitaria) núm. 144/2018 de 26 de marzo (AC 2018\1084); Asturias (Sección1a), sentencia núm. 628/2018 de 20 diciembre (JUR 2019\37639); Cádiz (Sección 5a) núm. 323/2019 de 25 de abril (JUR 2019\171339); Granada (Sección $3^{a}$ ) núm. 462/2019 de 14 de junio (JUR 2020\10237); Valladolid (Sección 3a) núm. 270/2019 de 25 de junio (JUR 2019\235023); Palencia (Sección1a), sentencia núm. 285/2019 de 30 julio (JUR 2019\267742); Madrid (Sección 28a) núm. 929/2019 de 11 septiembre (JUR 2020\71044); Zamora (Sección1a), sentencia núm. 397/2019 de 21 noviembre (JUR 2020\77246); León (Sección 1a) núm. 651/2019 de 26 de diciembre (JUR 2020\85709); Girona (Sección $1^{\text {a }) ~ n u ́ m . ~ 9 / 2020 ~ d e ~} 8$ de enero (JUR 2020\41798; Soria (Sección1 $1^{a}$ ) sentencia núm. 9/2020 de 13 enero (JUR 2020\86124); y Albacete (Sección 1a) núm. 138/2020 de 6 de abril (JUR 2020\156357), entre otras.

5 JUR $2018 \backslash 309449$.
} 
partes afectadas vuelvan a tener la situación patrimonial anterior al evento invalidador (SSTS 30-12-1996 y 15-04-2009)» [SAP de Pontevedra (Sección 6a) núm. 494/2017 de 3 de noviembre ${ }^{6}$. Esto supone, desde una perspectiva procesal, que la restitución de las cantidades abonadas por el prestatario «... no precise de una petición expresa de la parte (STS de 26-6-2006), de modo que el propio tribunal puede acordar la restitución en virtud del principio iura novit curia , sin que el juez incurra en incongruencia (STS antes citada de 8-1-2007, 24-2$1992,6-10-1994) \ldots$ » [SAP La Rioja (Sección 1a) núm. 332/2019 de 5 de septiembre ${ }^{7}$.

De lo contrario, la posibilidad de prescripción de una eventual acción para eliminar las consecuencias jurídicas de una cláusula declarada abusiva, conllevaría la convalidación de la eficacia de la cláusula nula, lo que sería contrario a la reiterada jurisprudencia del Tribunal Supremo que rechaza cualquier tipo de eficacia al acto jurídico nulo, en coherencia con lo dispuesto en el artículo 6.3 del Código Civil (STS 496/2008 de 29 de mayo), «... así como a lo dispuesto en los arts. 3 y 4 de la Directiva 93/13/CEE (...), quedando inane el principio de eficacia del Derecho de la UE en materia de cláusulas abusivas frente a los consumidores... » [SAP de Zaragoza (Sección 5a) núm. 329/2018 de 24 de abril ${ }^{8}$ ].

Además, cualquier limitación o restricción a la restitución de lo indebidamente abonado sería contrario al principio europeo de no vinculación pues, tal y como señala el apdo. 66 de la STJUE de 21 de diciembre de 2016 (asuntos C-154/15, C-307/15 y C-308/15), «...la declaración del carácter abusivo de la cláusula debe permitir que se restablezca la situación de hecho y de Derecho en la que se encontraría el consumidor de no haber existido tal cláusula abusiva, concretamente mediante la constitución de un derecho a la restitución de las ventajas obtenidas indebidamente por el profesional en detrimento del consumidor en virtud de la cláusula abusiva... » [SAP de Alicante (Sección 8a) núm. 138/2018 de 26 de marzo $^{9}$ ].

Por último, «... según reiteradísima jurisprudencia, la prescripción responde al principio de seguridad jurídica, por lo que ha de ser interpretada con carácter restrictivo: no puede prevalecer la seguridad jurídica sobre el derecho subjetivo, la acción se extingue por prescripción, pero el derecho no se extingue (la prescripción opera impidiendo el ejercicio de la acción para la protección del derecho). Por lo tanto, la seguridad jurídica no se puede anteponer a la nulidad por contravención de normas imperativas o prohibitivas (art. 6 CC): la seguridad jurídica no prevalece frente a un acto prohibido (contravención por abusividad, por ejemplo). En tanto en cuanto la Sala $1^{a}$ del Tribunal Supremo (o el TJUE) no cambie su criterio sobre la imprescriptibilidad en relación con los actos radicalmente nulos y sus consecuencias, este tribunal mantendrá el criterio

\footnotetext{
6 JUR $2017 \backslash 289466$.

7 JUR $2019 \backslash 272628$.

8 JUR $2018 \backslash 161007$.

9 JUR $2018 \backslash 163052$.
} 
anteriormente expresado...» [SAP de León (Sección 1a) núm. 378/2018 de 15 octubre $\left.{ }^{10}\right]$.

\subsection{Tesis sobre la aplicación del plazo prescriptivo quinquenal del art. 1964.2 CC}

La mayoría de la jurisprudencia ${ }^{11}$-sin dejar de reseñar las serias dudas de derecho que el tema suscita- admite que, si bien la acción declarativa de nulidad es imprescriptible, la acción de remoción de los efectos de la cláusula de gastos declarada nula es prescriptible, de conformidad con el principio general consagrado en el art. 1930 CC, estando sujeta al plazo del art. 1964.2 CC.

Uno de los fundamento para entender que se trata de dos acciones diferenciadas se basa en que, en el caso de la cláusula de gastos -y a diferencia de la cláusula suelo-, la entidad bancaria no percibió los importes cuya devolución se pretende; es decir, los pagos se realizaron a favor de terceros (bien en concepto de honorarios por su intervención profesional en la gestión, documentación o inscripción del contrato, bien porque el mismo está sujeto al devengo de determinados tributos, como el IAJD) distintos al predisponente de la cláusula nula (banco), por lo que no cabe hablar de restitución de las prestaciones ex art. 1303 CC. En efecto, para recuperar lo pagado a un tercero, en virtud de una cláusula abusiva y nula, deberá ejercitarse contra la entidad bancaria una acción de restitución de lo abonado basada en el pago de lo indebido o en el enriquecimiento injusto ${ }^{12}$.

Ejemplo de ello, es la AP Burgos (Sección 3a) núm. 445/2019 de 24 de septiembre ${ }^{13}$, la cual establece que «... el reintegro de las cantidades pagadas por el prestatario en concepto de gastos, por razón de la cláusula de gastos declarada nula por abusiva (...), no es una consecuencia derivada de la aplicación del art. 1.303 CC para las acciones de nulidad, y ello por la sencilla razón que tal precepto legal impone a las partes de un contrato declarado nulo la obligación de restituir a la otra parte las cantidades cobradas por razón del mismo más los intereses legales devengados desde su cobro, siendo el caso que el banco prestamista no ha percibido las cantidades cuyo reintegro se reclaman, dado que las mismas fueron pagadas a terceros (notario, registrador, gestor, tasador) que tienen

\footnotetext{
10 JUR $2018 \backslash 309449$.

11 Sentencias de las AAPP de A Coruña (Sección 4a) núm. 411/2017 de 29 de noviembre (JUR 2018\27770); Pontevedra núm. 226/2019 de 23 abril (JUR 2020\276886); Alicante (Sección 8a) núm. 583/2019 de 13 mayo (JUR 2019\256762); Teruel (Sección 1a) núm. 164/2019 de 5 de junio (JUR 2019\226664); Valencia (Sección 9a) núm. 829/2019 de 25 de junio (JUR 2019\236104); Burgos (Sección 3a) núm. 445/2019 de 24 de septiembre (JUR 2019\291841); Islas Baleares (Sección 5a) núm. 772/2019 de 12 de noviembre (AC 2020\84); Palencia (Sección $1^{\text {a }}$ ) núm. 399/2019 de 19 de noviembre; Zaragoza (Sección 5a) núm. 958/2019 de 27 de noviembre (JUR 2020\8502); Zaragoza (Sección 5a) núm. 1071/2019 de 17 diciembre (JUR 2020\43327); Madrid (Sección 28a) núm. 779/2020 de 19 de marzo (JUR 2020\176402); Murcia (Sección 4a) núm. 311/2020 de 2 abril (AC 2020\1167); y Santa Cruz de Tenerife (Sección 4aa) núm. 631/2020 de 29 de junio (JUR 2020\347486), entre otras.

12 Doctrina jurisprudencial emanada de las SSTS núm. 44/2019, 46/2019, 47/2019, 48/2019 y $49 / 2019$ de 23 de enero.

13 JUR $2019 \backslash 291841$.
} 
Se reaviva el debate sobre la prescripción de la acción de restitución de los gastos hipotecarios tras la nota informativa del Ministerio de

derecho a percibir tales cantidades en concepto de arancel u honorarios y no están obligados a devolverlas. Señala nuestro Alto Tribunal (...) que la declaración de nulidad por abusiva de la cláusula de gastos conlleva que la misma se tenga por no puesta o inexistente, y que se restituya a las partes en la situación fáctica y jurídica que hubiera existido de no haber mediado de dicha cláusula, de tal forma que cada una de ellas sólo estaría obligada a pagar los gastos cuyo pago le corresponda conforme la normativa vigente en el momento en que se otorgó la escritura. La consecuencia de lo anterior es que el banco sólo está obligado a reintegrar las cantidades que en concepto de gastos hubiera tenido que pagar el prestamista y cuyo pago por el prestatario debe ser considerado indebido, dado que en tal caso el banco ha obtenido una ventaja indebida por razón de la una cláusula que ha sido declarada nula por abusiva (...). En tal sentido la restitución de las cantidades abonadas de forma indebida por el prestatario (...) no tiene su fundamento directo en la aplicación del art. 1.303 CC sobre la acción de nulidad, sino en la existencia de un pago indebido o de una situación de enriquecimiento injusto a favor del banco prestamista y en perjuicio del prestatario consumidor, dado que por el pago de los gastos se ha producido un desplazamiento patrimonial que ha perjudicado al prestatario, que de no haber mediado la cláusula no debería haber pagado tales gastos indebidos y a su vez ha beneficiado de modo indebido al banco prestamista que se ha visto liberado del pago de unos gastos que de no haber mediado la cláusula hubiera tenido que haber pagado por ser de su cargo (...). [En efecto], tal acción de reintegración debe ser considerada como una acción autónoma de la acción de nulidad, y sometida a un plazo propio de prescripción, que no es otro que el plazo general de los quince años establecido por el art. 1964 CC para todas las acciones personales que no tienen un plazo propio.... ».

Por otro lado, la SAP de Barcelona (Sección 15a) núm. 1694/2020 de 10 de julio ${ }^{14}$ se apoya en el principio de seguridad jurídica, consagrado en el art. 9.3 CE, para justificar la existencia de dos acciones diferenciadas. Dice así: «... [si bien es cierto que con respecto a] la prescripción de la acción de remoción de los efectos de una condición general nula por abusiva cuando los efectos de la cláusula ya se han producido (...), la jurisprudencia del Tribunal Supremo no es uniforme, pues mientras la STS de 27 de febrero de 1964 (RJ 1964, 1152) descarta que las acciones restitutorias de actos o contratos nulos sean imprescriptibles (...), la más reciente STS de 25 de marzo de 2013 (RJ 2013, 4596), en un supuesto de nulidad absoluta por simulación -no de nulidad por infracción de norma imperativa-, considera que "la restitución de los bienes está sometida al mismo régimen de imprescriptibilidad que la acción declarativa de la simulación, por cuanto nada deriva de la nada -ex nihilo nihil-" (...) estimamos que si el consumidor, en cumplimiento de lo previsto en la cláusula abusiva, ha abonado alguna cantidad y, en definitiva, la cláusula ha desplegado y agotado sus efectos, por razones de seguridad jurídica, la acción de remoción de los efectos de la nulidad se extingue por el transcurso del tiempo. No nos parece razonable (...) que la reclamación de gastos de gestoría, notaría o registro no se sujete a un plazo de prescripción y que puedan exigirse esos gastos, con sus intereses, aunque se hayan abonado hace

${ }^{14}$ AC $2020 \backslash 1065$. 
Se reaviva el debate sobre la prescripción de la acción de restitución de los gastos hipotecarios tras la nota informativa del Ministerio de

décadas o incluso siglos con pleno conocimiento por parte del consumidor. Resulta imprescindible asegurar un mínimo de certidumbre a las relaciones jurídicas, que no pueden estar amenazadas de esa forma por tiempo indefinido (...). No estimamos que estemos ante una única acción de nulidad imprescriptible y que no podamos distinguir, como hace de forma casi unánime la doctrina, entre la acción declarativa de nulidad y la acción de remoción de los efectos. Frecuentemente ambas acciones se han ejercitado de forma separada. De hecho, este Tribunal sólo ha tenido ocasión de pronunciarse, hasta el momento, sobre acciones meramente declarativas de nulidad de la cláusula de gastos [y] el Tribunal Supremo, de igual modo, conoció de una acción colectiva de nulidad [Sentencia de 23 de diciembre de 2015 (RJ 2015, 5714)]. Sobre la base del carácter abusivo de la atribución sin matices de todos los gastos al prestatario, la reciente STS de 15 de marzo de 2018 $(R J$ 2018, 1241) señala que deben ser los tribunales quienes decidan y concreten "en procesos posteriores, ante las reclamaciones individuales de los consumidores, cómo se distribuyen en cada caso los gastos e impuestos de la operación". Esa acción presenta perfiles propios y apreciamos su carácter autónomo respecto de la acción principal de nulidad (...). La remoción de efectos, por otro lado, no es automática, dado que para la distribución de los gastos habrá que estar a lo que dispongan las Leyes sectoriales $y$ a las particulares circunstancias de cada caso (parte que ha solicitado los servicios o en cuyo interés se han prestado, acuerdos entre los contratantes... )».

La SAP de Murcia (Sección 4a) núm. 993/2019 de 19 de diciembre ${ }^{15}$, por su parte, recurre al Derecho de la Unión europea para justificar la disociación de las dos acciones: «...el tiempo no sana la nulidad, pero si se quiere, sí viene a consolidar esa situación fáctica (aquí, el desplazamiento patrimonial), no obstante ser nulo el título que lo desencadena (...). La aplicación de la prescripción a la acción de recuperación de sumas pagadas indebidamente, no se considera contraria a la normativa europea de protección de los consumidores. [Si bien] no desconocemos que la Sentencia del TJUE de 21 de diciembre de 2016 (asunto Gutiérrez Naranjo) declara en el apartado 66 que "... la declaración del carácter abusivo de la cláusula debe permitir que se restablezca la situación de hecho y de Derecho en la que se encontraría el consumidor de no haber existido tal cláusula abusiva, concretamente mediante la constitución de un derecho a la restitución de las ventajas obtenidas indebidamente por el profesional en detrimento del consumidor en virtud de la cláusula abusiva...", [en el apdo. 69] admite la existencia de plazos de prescripción, al decir que "... del mismo modo, el Tribunal de Justicia ya ha declarado que la fijación de plazos razonables de carácter preclusivo para recurrir, en interés de la seguridad jurídica, es compatible con el Derecho de la Unión"(...). Lo que el TJUE dice es que la doctrina del TS, que limitaba en el tiempo los efectos jurídicos derivados de la declaración de nulidad de las cláusulas suelo, es contraria a la Directiva 93/13, al implicar la fijación de límites temporales en la interpretación de Derecho de la Unión interpretado por el TJUE, que solo a este le corresponde efectuar. Pero ello no significa que sea incompatible con la Directiva 93/13 una normativa que prevea un plazo para el ejercicio de la acción

15 JUR $2020 \backslash 89390$. 
Se reaviva el debate sobre la prescripción de la acción de restitución de los gastos hipotecarios tras la nota informativa del Ministerio de

encaminada a restablecer la situación y la restitución de las ventajas obtenidas indebidamente por el profesional en detrimento del consumidor en virtud de la cláusula abusiva (...). En definitiva, la prescripción de la acción restitutoria no resulta contraria al artículo $6.1^{\circ}$ de la Directiva 93/13, ya que el plazo de prescripción de las acciones personales en el Derecho español resulta "razonable"... ».

Respecto al porqué es de aplicación el plazo prescriptivo del art. 1964.2 CC, la SAP Salamanca (Sección1 ${ }^{a}$ ) núm. 362/2020 de 24 julio $^{16}$ declara que «... frente al plazo de cuatro años previsto en el art. 1303 CC y que resulta aplicable únicamente en los supuestos de anulabilidad, en los casos de nulidad radical, como sucede con las cláusulas abusivas, el plazo de prescripción aplicable será el establecido con carácter general para las obligaciones en el art. 1964 CC; plazo que deberá aplicarse en la forma prevista en la Disposición transitoria quinta de la Ley 42/2015 de 5 de octubre, de reforma de la Ley de Enjuiciamiento Civil, en virtud de la cual el plazo de prescripción para el ejercicio de las acciones personales pasó a ser de quince a cinco años, disponiendo además -por remisión al art. 1939 del Código Civil- que las acciones personales nacidas antes de la fecha de entrada en vigor del nuevo plazo prescriptivo, el 7 de octubre de 2015, no prescribirán hasta que transcurran cinco años desde la entrada en vigor de esta modificación legal, es decir, hasta el 7 de octubre de 2020, salvo que hubieran de prescribir antes de esa nueva regla (el mencionado de 7 octubre de 2015), con arreglo al plazo de prescripción anterior de 15 años... ${ }^{17}$. En términos similares la SAP de Valencia (Sección 9a) núm. 829/2019 de 25 de junio (JUR 2019\236104).

\section{Dies a quo para el cómputo del plazo de prescripción de la acción restitutoria}

Entre las resoluciones judiciales que admiten la posibilidad de prescripción de la acción de restitución de los gastos hipotecarios (art. 1964.2 CC), se erigen tres líneas de actuación sobre el momento en el que comienza a correr el plazo de prescripción: (1) unas resoluciones acuden a la fecha de pago de las facturas; (2) otras vinculan el inicio del plazo con la publicación de la STS de 23 de diciembre de 2015; (3) y una tercera línea retrasa el inicio del cómputo al momento en que se declare judicialmente la nulidad de la cláusula.

\footnotetext{
16 JUR $2020 \backslash 276886$.

17 Por el contrario, una parte de la doctrina científica secunda la tesis de que la acción de restitución debe ejercitarse en el plazo de 4 años previsto en el artículo 1.301 CC, pues la abusividad no se trata de una nulidad absoluta o radical, sino de un supuesto de anulabilidad que afecta al consentimiento prestado. Véase CARRASCO PERERA, A.: «La acción para reclamar intereses pagados en virtud de una cláusula suelo está prescrita cuando han transcurrido cuatro años desde que el contrato hipotecario ha sido consumado y cancelado», Revista CESCO de Derecho de Consumo, núm. 21/2017, pág. 105.
} 
Se reaviva el debate sobre la prescripción de la acción de restitución de los gastos hipotecarios tras la nota informativa del Ministerio de

\subsection{Tesis que fija el dies a quo en el momento que se hicieron efectivos los pagos}

Un sector de la denominada jurisprudencia menor ${ }^{18}$ ha venido entendiendo que siendo el plazo de prescripción para reclamar las cantidades debidas el de cinco años previsto para las acciones personales en el art. 1964.2 CC, el dies a quo tiene que fijarse en el momento que el consumidor efectuó las prestaciones a favor de terceros en virtud de la cláusula abusiva y nula, esto es, a partir del momento en que realizó los pagos indebidos, «pues fue en ese momento cuando nació la acción de restitución de conformidad con una interpretación objetiva del art. 1969 CC (teoría de la actio nata)... » [AP de Palencia (Sección 1a) núm. 399/2019 de 19 de noviembre ${ }^{19}$ ].

Además, rechazan que pueda situarse el inicio del cómputo en otro momento distinto. Así, la SAP de Valencia (Sección 9a) núm. 66/2018 de 1 de febrero ${ }^{20}$, señala que el dies a quo del cómputo no puede vincularse a la STS de 23 de diciembre de 2015 «... por varias razones: una, y principal, porque las sentencias no son equiparables a las leyes, no son fuentes del ordenamiento jurídico, aunque las del Tribunal Supremo lo completen con la doctrina reiterada que establezcan al interpretar esas fuentes, por lo que no puede exigirse que la generalidad de los ciudadanos las conozcan, ni siquiera sentencias de tanta repercusión como la citada o la que se dictó sobre la "cláusula suelo", STS de 9 de mayo de 2013; segundo, porque la STS de 23 de diciembre de 2015 resuelve un recurso de casación y en el procedimiento la sentencia de primera instancia ya había declarado cláusulas nulas por abusivas, lo que supone, obviamente, que ya hubo consumidores que pudieron antes ejercitar la acción aunque fuera la de nulidad (no se olvida que no se ejercitaba la acción de restitución en ese caso). También se rechaza que el plazo deba computarse desde que la concreta cláusula incluida en el contrato que celebra el consumidor sea declarada nula; y ello porque, en primer lugar, tratándose de una nulidad absoluta o de pleno derecho, la de la cláusula, el ejercicio de la acción de nulidad no siempre sería necesario (p.ej., la entidad bancaria reconoce extraprocesalmente la nulidad pero no se aviene a restituir al consumidor todo o parte de lo pagado en virtud de esa cláusula); y en segundo lugar, porque de aceptarse esta tesis no sólo la acción de nulidad sería imprescriptible sino que también lo sería la acción de restitución. Si lo que es nulo no produce ningún en efecto y es nulo desde que el primer momento y para siempre, "de aquí a la eternidad", resultaría que la restitución podría ejercitarse hasta la eternidad y cinco años más, lo que resulta absurdo. Descartadas las anteriores opciones, si la acción de nulidad puede ejercitarse desde el día siguiente

\footnotetext{
18 Sentencias de las AAPP de Barcelona (Sección 15a) núm. 547/2018 de 25 julio (JUR 2018\258261); Badajoz (Sección 2a) núm. 211/2019 de 25 de marzo (AC 2019\436); Valencia (Sección 9a) núm. 586/2019 de 8 de mayo (AC 2019\1008); Alicante (Sección 8a) núm. 583/2019 de 13 de mayo (JUR 2019\256762); Zaragoza (Sección 5a) núm. 578/2019 de 5 de julio (RJ 2019\250804); Burgos (Sección 3a) núm. 445/2019 de 24 de septiembre (JUR 2019\291841); A Coruña (Sección 4a) núm. 506/2019 de 30 diciembre (JUR 2020\101905); y Barcelona (Sección 15a) núm. 116/2020 de 22 de enero (AC 2020\16), entre otras.

${ }^{19}$ AC 2020\1091.

20 JUR 2018\131835.
} 
a la celebración del contrato, la acción de restitución puede ejercitarse a partir de que el consumidor efectuó prestaciones a favor del empresario en virtud de la cláusula abusiva y nula, esto es, a partir del momento en que realizó los pagos indebidos... ».

La SAP de Murcia (Sección $4^{a}$ ) núm. 34/2019 de 10 de enero ${ }^{21}$ añade otros motivos de refuerzo para rechazar la tesis que sitúa el dies a quo en la STS de 23 de diciembre de 2015: «... (i) las sentencias del TS - y de igual forma las del TJUEse limitan a aclarar y precisar, cuando es necesario, el significado y alcance del Derecho (...), por lo que no podemos tomar la fecha en que se dicta una sentencia como dies para el ejercicio de una acción que ya se tenía antes, pues esa sentencia del TS que se invoca carece de efectos constitutivos; (ii) para el ejercicio de la acción de reclamación no es necesaria la previa declaración judicial de nulidad, que solo se hará si ésta se cuestiona; ello es característico de la nulidad de pleno derecho (se produce "ipso iure", por sí misma y sin necesidad de intervención judicial), por lo que no es cierto que no quepa su ejercicio sin previa declaración judicial, y (iii) el nuevo art 1.964CC, que no es aplicable pero que sirve de guía o parámetro exegético, aclara que las acciones personales que no tengan plazo especial prescriben ahora a los cinco años "desde que pueda exigirse el cumplimiento de la obligación. En las obligaciones continuadas de hacer o no hacer, el plazo comenzará cada vez que se incumplan". Por tanto, se considera que puede ejercitarse desde que puede exigirse su cumplimiento, y este momento no es otro que desde que se hizo el pago impuesto de forma abusiva... ».

\subsection{Tesis que vincula el dies a quo con la publicación de la STS de 23 de diciembre de 2015}

Otras sentencias defienden que el plazo para el ejercicio de la acción restitutoria debe computarse desde la primera sentencia del Tribunal Supremo en la que se declaró la nulidad de la cláusula de gastos, lo que tuvo lugar en la sentencia de 23 de diciembre de 2015 -publicada el 21 de enero de 2016 -, pues «... ese día los usuarios tomaron conocimiento del carácter abusivo de la cláusula» [SAP de Lugo núm. 371/2019 de 11 septiembre ${ }^{22}$ ].

Sin embargo, la misma Audiencia Provincial de Lugo, en la sentencia núm. 283/2019 de 2 de mayo ${ }^{23}$ arguyó, tras rechazar la tesis que fija el dies a quo en el momento del pago de las facturas y la otra que fija el inicio desde que se declara la nulidad de la cláusula ( «...no compartimos la tesis de aquellas sentencias que fijan tal hito temporal cuando se abonaron los gastos, pues en aquel momento no conocía el consumidor la abusividad de la cláusula, su nulidad, ni las acciones que de ello derivan. Tal solución interpretativa deja al consumidor en una situación de indefensión constriñéndole a una victoria pírrica en la que obtiene una declaración de nulidad estéril o inocua, pues no va más allá de ese efecto mero declarativo sin contenido económico. Desde la posición contraria, situar el inicio del cómputo en el momento de la declaración de abusividad comporta "de facto" una acción de

\footnotetext{
${ }^{21}$ AC $2019 \backslash 320$.

22 JUR $2019 \backslash 273065$.

23 JUR $2019 \backslash 144266$.
} 
enriquecimiento injusto imprescriptible lo que no es la solución adoptada por nuestro derecho interno»), que «... una opción es fijar, entonces, el día de inicio del plazo en la fecha de la sentencia de 23 de diciembre de 2015 , que fue el momento de la declaración inicial de nulidad en el seno de una acción colectiva. Sin embargo, tal sentencia no marco con la debida concreción los efectos de la nulidad que fue algo que no se produjo por nuestro Tribunal Supremo sino hasta la sentencia de 23 de enero de 2019 en la que ya el Tribunal Supremo sienta en plenitud doctrina jurisprudencial sobre la cláusula de gastos y los efectos derivados de la misma, [por lo que] el inicio del cómputo en estos supuestos de gastos hipotecarios se sitúa en el 23 de enero de 2019» (FJ 20).

Ante la duda sobre si situar el inicio del cómputo desde la STS de 23 de diciembre de 2015 o desde las SSTS de Pleno de 23 de enero de 2019, la AP de Valladolid (Sección $3^{a}$ ) núm. 676/2020 de 21 de octubre ${ }^{24}$ aplica indistintamente ambos criterios. En concreto sostiene que mientras no se resuelva legislativamente o se fije un criterio que evite la inseguridad jurídica, «... parece lógico entender que el plazo debe computarse, bien desde la primera sentencia dictada por el TS declarativa de la nulidad de la cláusula de gastos, es decir, la de 23 de diciembre de 2015, que además tuvo una amplia resonancia en los medios de comunicación, lo que permitió un conocimiento general de la misma, o bien desde la sentencia de enero de 2019, en la que se precisan los criterios de distribución de los gastos sobre los que no existía uniformidad en la doctrina» (FJ $4^{\circ}$ ).

\subsection{Tesis que retrasa el dies a quo al momento en el que se declare judicialmente la nulidad de la cláusula}

Por último, un tercer sector jurisprudencial ${ }^{25}$ retrasa el momento del cómputo del plazo al día en que se declare judicialmente la nulidad de la cláusula de gastos porque «...la acción de restitución, reclamación o enriquecimiento es, en todo caso, accesoria a la acción de nulidad -puesto que sin ésta última, la acción de restitución no existiría-, por lo que resulta adecuado considerar que el plazo de prescripción para el ejercicio de esta acción quede subordinada a la declaración judicial de nulidad. $Y$ así, ejercitadas en el mismo proceso acciones de nulidad y acciones de restitución, ninguna de estas se encontraría prescrita, por la imprescriptibilidad del ejercicio de la acción de nulidad y por la accesoriedad de las segundas... » [SAP Madrid (Sección $8^{a}$ ) núm. 191/2018 de 7 de mayo ${ }^{26}$ ].

La SAP de Lleida (Sección 2a) núm. 80/2020 de 31 de enero (JUR 2020\59261) sostiene que «... olvida la recurrente que los prestatarios no han podido ejercitar la acción de reembolso o reintegro de las cantidades que pagaron por gastos notariales, registrales y de gestoría hasta que ha sido declarada la nulidad de la

\footnotetext{
24 JUR $2020 \backslash 333858$.

25 Sentencias de las AAPP de Vizcaya (Sección 4a) núm. 176/2018 de 22 marzo (AC 2018\184); Teruel (Sección1a) núm. 164/2019 de 5 junio (JUR 2019\226664); Granda (Sección 3a) núm. 603/2019 de 9 de septiembre (JUR 2020\10650); Zamora (Sección1a) núm. 292/2019 de 9 septiembre (JUR 2019\275739); Tarragona (Sección1a) núm. 463/2019 de 10 octubre (JUR 2019\295568); Cádiz (Sección 5a) núm. 255/2020 de 19 de marzo (JUR 2020\219147); y Ciudad Real (Sección 1a) núm. 559/2020 de 23 de octubre (ECLI: ES:APCR:2020:1582), entre otras.

${ }^{26}$ RJ $2018 \backslash 212124$.
} 
Se reaviva el debate sobre la prescripción de la acción de restitución de los gastos hipotecarios tras la nota informativa del Ministerio de

cláusula quinta de la escritura de préstamo con garantía hipotecaria, lo cual no ha sucedido hasta este procedimiento. Hasta su declaración de nulidad nada podían reclamar los prestatarios precisamente por los propios efectos de la citada disposición contractual, de forma que el plazo de prescripción para poder reclamar su reintegro, que constituye una acción personal, no puede empezar a contar hasta que se produce su declaración de nulidad pues es cuando nace para el acreedor la posibilidad de ejercitar la acción en virtud del principio de la "actio nata" (art. 1969 del CC). Como dice la STS de 22-5-08, citada por la de 25-3-09: "nuestro Código civil, superando la teoría de la "actio nata", afirmativa para ser posible la prescripción, de que la acción hubiera nacido, dejando sin resolver la cuestión de cuándo debe entenderse que nació, afecta, a través de la normativa del artículo 1969 de dicho Código, la teoría de la realización, sosteniéndose el nacimiento de la acción cuando puede ser realizado el derecho que con ella se actúa, o más concretamente al tiempo al que pudiere ejercitarse eficazmente para lograr su total efecto, según tiene reconocido este Tribunal en Sentencias de 26 de noviembre de 1943, 29 de enero de 1952 y 25 de enero de 1962 , reiterando criterio ya sostenido en otras precedentes, porque, como se proclama en la última de las relacionadas resoluciones, si la prescripción extintiva comenzara a correr antes de que la acción pudiera ejercitarse, se daría el contrasentido de que se castigaba al titular de un derecho por una inactividad que le imponía la Ley o la propia convención, y de ahí que no se pueda reprochar al titular de un derecho el no haberlo actuado en una época en la cual no podía ponerlo normal y eficazmente en ejercicio, por no conocer todavía las bases para actuario"...».

Por último, la AP Pontevedra (Sección1a), sentencia núm. 226/2019 de 23 abril (JUR 2019\177075) mantiene que «... la acción de restitución de las consecuencias de la declaración de nulidad de un contrato o una cláusula contractual exige, como presupuesto esencial, que se haya admitido por las partes o declarado por sentencia judicial la nulidad en cuestión, ya que, hasta ese momento, el contrato o la condición general de la contratación despliega todos sus efectos obligacionales. No es posible el ejercicio autónomo de una acción de reposición si, previa o simultáneamente, no se ejercita la acción de nulidad del contrato o la cláusula. En concreto, por asimilación a la acción de enriquecimiento injusto o pago de lo indebido, es preciso que la pretensión se asiente en la injusticia o falta de causa del enriquecimiento o del pago, lo cual, habiéndose fundado la transmisión en un obligación negocial, requiere la eliminación por vía de nulidad de pleno derecho de dicha obligación. Por tanto, la acción de restitución puede ejercitarse, y el plazo de prescripción comienza a correr, desde que se declara la nulidad de pleno derecho del contrato o cláusula contractual, declaración que constituye el título constitutivo sobre el que se apoya la acción de restitución, como expresamente afirma la STJUE de 31 de mayo de 2018, asunto C-483/2016, caso Zsolt Sziber y ERSTE Bank Hungary Zrt (...). La tesis sostenida por la entidad demandada (la prescripción comienza a computarse desde la celebración del contrato y asunción y pago por el prestatario de los conceptos recogidos en la cláusula de gastos), implicaría que, transcurridos cinco años desde la celebración del contrato, el consumidor ya no podría reclamar la devolución de las cantidades satisfechas en virtud de una cláusula declarada nula por abusiva, lo cual, tratándose contratos de larga duración, comporta un riesgo no desdeñable de que 
Se reaviva el debate sobre la prescripción de la acción de restitución de los gastos hipotecarios tras la nota informativa del Ministerio de

el consumidor afectado no realice la reclamación dentro del citado plazo, ya sea debido al tiempo que haya tardado en revelarse el carácter abusivo de la cláusula, ya sea porque ignora o no percibe la amplitud de sus derechos, por lo que la protección del consumidor resultaría incompleta e insuficiente y no constituiría un medio adecuado y eficaz para que cese el uso de ese tipo de cláusulas, en contra de lo que establece el artículo 7.1 de la Directiva 93/13 (véase, en este sentido, la sentencia de 14 de marzo de 2013, Aziz, C 415/11, EU:C:2013:164, apartado 60). Al amparo de estas consideraciones, procede declarar que el día inicial para el cómputo del plazo de prescripción de la acción de restitución de las consecuencias derivadas de la declaración de nulidad de una cláusula contractual, si no se hubiera ejercitado conjuntamente con la acción de nulidad, es el de la firmeza de la sentencia que así la declare...» (FJ $2^{\circ}$ ).

\section{Crítica a la nota informativa del Ministerio de Consumo}

En medio de esta tormenta interpretativa, el Ministerio de Consumo hizo pública una nota informativa en la que fija el dies a quo del cómputo del plazo de prescripción de la acción restitutoria desde el momento que el Tribunal Supremo se pronunció sobre la abusividad de la cláusula que imputa todos los gastos hipotecarios al prestatario en la sentencia de 23 de diciembre de 2015.

La propia introducción de la citada nota («[e]n diciembre de 2015, el Tribunal Supremo dictaminó que aquellas cláusulas en contratos de préstamo hipotecario que hiciesen recaer sobre el prestatario todos los gastos de constitución de una hipoteca debían ser consideradas abusivas... ») hace presagiar la postura que va a adoptar el Ministerio cuando posteriormente se pregunta sobre cuál es el plazo para poder reclamar la devolución de los gastos.

Efectivamente, apoyándose en la STS de 23 de diciembre de 2015, responde que «[e]l plazo para solicitar la devolución de gastos derivados de una cláusula declarada abusiva es de cinco años, plazo que, de acuerdo con el Tribunal de Justicia de la Unión Europea, no podría comenzar a computar hasta que la persona afectada pudiese haber tenido conocimiento razonablemente del carácter abusivo de la cláusula en cuestión. En relación con la cláusula de gastos ya declarada abusiva (la que incluye los gastos de gestoría, registro de la propiedad y notaría, así como el impuesto $A J D)$, se puede entender que se pudo tener conocimiento del carácter abusivo de la misma desde el momento que se hizo pública la Sentencia del Tribunal Supremo, el 21 de enero de 2016».

Es totalmente inaudito que el Ministerio dé por válida una de las tesis y destierre las otras existentes, máxime cuando todavía se sigue debatiendo en los tribunales si la acción de restitución está o no sometida a prescripción, y de ser prescriptible, cuál es el plazo aplicable y el dies a quo del cómputo.

Además, adopta erróneamente uno de los criterios existentes pues, como se verá seguidamente, no procede tomar la fecha en la que se dicta una sentencia del Alto Tribunal como dies a quo para el ejercicio de la acción de restitución. 
Partiendo que el plazo de prescripción aplicable a la acción de restitución de los gastos es el quinquenal del art. 1964.2 CC, este mismo precepto establece que las acciones personales que no tengan plazo especial prescriben a los cinco años «desde que pueda exigirse el cumplimiento de la obligación». En parecidos términos se pronuncia el art. 1969 CC, el cual instaura la regla general del dies a quo del plazo de prescripción: «[e]l tiempo para la prescripción de toda clase de acciones, cuando no haya disposición especial que otra cosa determine, se contará desde el día en que pudieron ejercitarse».

El art. 1969 CC no determina con exactitud el momento a partir del cual empieza a correr el plazo prescriptivo, sino que se limita a formular una regla abierta («desde que pudieron ejercitarse») que plantea el problema de determinar en qué momento es posible ejercitar la acción.

La jurisprudencia clásica del TS 27 ha venido sosteniendo que el art. el art. 1969 CC debe ser interpretado en clave objetiva, de tal manera que para que el plazo prescriptivo comience a correr es necesario, única y exclusivamente, que la acción entendida como pretensión- haya nacido -doctrina de la actio nata-, al margen de las circunstancias subjetivas del potencial actor. En palabras de DÍEZ-PICAZO28, «la "posibilidad" a que alude el art. 1969, es la "posibilidad legal" y, por tanto, las condiciones materiales del interesado $u$ otras circunstancias puramente personales sólo podrán tenerse en cuenta excepcionalmente cuando la ley así lo determine».

En cambio, desde la STS núm. 728/2012 de 11 de diciembre ${ }^{29}$-con precedentes en las SSTS de 25 de enero de 1962, de 27 de mayo de $2002^{30}$ y de 5 de junio de $2008^{31}$ - el Alto Tribunal parece haber dejado a un lado la interpretación objetiva del art. 1969 CC para dar paso a una interpretación subjetiva del mismo, debiendo tomarse en consideración, no ya solo el nacimiento de la acción (actio nondum nata non praescribitur), sino también las circunstancias personales y materiales que afectan al titular de la acción. Así, tal y como pone de manifiesto MARÍN LÓPEZ ${ }^{32}$, «para que el plazo de prescripción comience a correr deben concurrir tres requisitos: (i) que exista la posibilidad jurídica de ejercitar la pretensión, esto es, que la pretensión haya nacido y sea jurídicamente ejercitable; (ii) que el acreedor tenga la posibilidad real y efectiva de ejercitar la pretensión, esto es, que no concurra una circunstancia (fuerza mayor) que le impida reclamar; y (iii) que el acreedor conozca,

\footnotetext{
27 Sentencias de 25 de noviembre de 1895 (ECLI: ES:TS:1903:1306); de 18 de noviembre de 1963 (ECLI: ES:TS:1963:2873); núm. 1119/1994 de 13 diciembre (RJ 1994\9420) y núm. 763/2001 de 19 julio (RJ 2001\6862), entre otras. Vid. sentencias citadas en DOMÍNGUEZ MARTÍNEZ, P.: «Comentario al art. 1969 del CC», en BERCOVITZ ROdRÍGueZ-CANO, R. (Coord.), Comentarios al Código Civil, 3.a ed., Ed. Aranzadi, Navarra, 2009, pág. 1. http://aranzadi.aranzadidigital.es.

28 DÍEZ-PICAZO Y PONCE DE LEÓN, L.: «Presupuestos de ejercicio de la facultad de prescripción», La prescripción extintiva en el Código civil y en la jurisprudencia del Tribunal Supremo, 2.a ed., Ed. Cívitas, Madrid, 2007, pág. 6. http://aranzadi.aranzadidigital.es.

${ }^{29}$ RJ $2013 \backslash 4350$.

30 RJ $2002 \backslash 7251$.

${ }^{31}$ RJ 2008\4239.

32 MARÍN LÓPEZ, M.J.: «La prescripción de la acción de nulidad de la cláusula de gastos y de la acción de restitución de los gastos abonados», Revista CESCO de Derecho de Consumo, núm. 22/2017, pág. 93.
} 
o debiera haber conocido si hubiera con la diligencia debida, los hechos que fundamentan su pretensión y la identidad de la persona contra la que reclamar».

Determinadas las dos líneas interpretativas existente en cuanto al inicio del cómputo del plazo de prescripción, si el art. 1969 CC fuera interpretado objetivamente, la acción de restitución de los gastos abonados podría ejercitarse, y por tanto el plazo quinquenal del art. 1964.2 CC comenzaría a computarse, desde que se realizan los pagos indebidos cuya restitución se reclama ${ }^{33}$. Y ello porque la nulidad de la cláusula de gastos es una nulidad ipso iure -la cláusula siempre ha sido nula- y por tanto, la sentencia judicial es declarativa y no constitutiva de dicha nulidad ${ }^{34}$.

Por el contrario, si se interpretara subjetivamente el art. 1969 CC ¿cabría sostener que el dies a quo se sitúa desde la STS de 23 de diciembre de 2015 ? Es cierto que los consumidores tuvieron conocimiento de la abusividad y nulidad de la cláusula de gastos cuando el TS se pronunció sobre la validez de la misma en la sentencia de 23 de diciembre de 2015, más concretamente desde que se hizo pública el 21 de enero de 2016, por lo que podría sostenerse que, con anterioridad a la mencionada sentencia, los prestatarios no pudieron ejercitar la acción correspondiente al faltar uno de los elementos (jurídicos) necesarios para plantearla: conocimiento de la abusividad de la cláusula. Sin embargo, este argumento no puede prosperar por las siguientes razones.

En primer lugar, la jurisprudencia no es ley, no es fuente del ordenamiento jurídico, sino que se limita a completarlo, por lo que no puede exigirse a la generalidad de los ciudadanos que la conozcan, ni siquiera sentencias de tanta repercusión como la STS de 23 de diciembre de $2015^{35}$. Además, tampoco es precedente vinculante, pues si así fuera «podríamos caer en la siguiente paradoja: si la acción no "pudo" ejercitarse sino desde la STS de 23 de diciembre de 2015 ¿cómo pudo ser ejercitada previamente por otros consumidores? [V.gr. SAP de Pontevedra núm. 175/2014 de 14 mayo (JUR 2014\145294)]»36.

En segundo lugar, no puede vincularse el dies a quo para el ejercicio de la acción de restitución a la fecha de publicación de la STS de 23 de diciembre de 2015 máxime cuando el propio Tribunal de Luxemburgo señaló, en la conocida sentencia de 21 de diciembre de 2016, que la fecha de publicación de la STS (Sección Pleno) núm.

\footnotetext{
33 CAÑIZARES LASO, A.: «Algunas claves para la reforma de la prescripción. En especial el dies a quo», Revista de Derecho Civil, Vol. V, núm. 4/2018, págs. 101-104 y 107-108; y PEÑA LÓPEZ, F.: «El dies a quo y el plazo de prescripción de las acciones de responsabilidad por daños en el CC: criterios procedentes de algunos textos europeos de soft law y del Derecho estadounidense que podrían servir para su reforma e interpretación», InDret, núm. 4/2011, pág. 4.

34 MIQUEL GONZÁLEZ, J.M.: «La acción de nulidad no es una acción porque no entraña una pretensión», Almacén de Derecho, 2017. Disponible en: https://almacendederecho.org/la-accion-nulidad-no-unaaccion-no-entrana-una-pretension (Consultado: 4/01/2021).

${ }^{35}$ SAP de Valencia (Sección 9a) núm. 66/2018 de 1 de febrero (JUR 2018\131835).

36 AGÜERO ORTIZ, A.; MENDOZA LOSANA, A.I. y PARRA MEMBRILLA, L.: «Protección del consumidordeudor hipotecario: realidad y perspectivas de futuro. Acta del Curso de Verano, Cuenca 3 y 4 de julio de 2017», Revista CESCO De Derecho De Consumo, núm. 22/2017, pág. 16.
} 
241/2013 de 9 de mayo ${ }^{37}$ no podía suponer un límite a la retroactividad de los efectos de la declaración de nulidad de la cláusula suelo.

En tercer y último lugar, como bien ponen de manifiesto CARRASCO PERERA ${ }^{38}$ y MARÍN LÓPEZ ${ }^{39}$, el conocimiento que se exige para que comience a correr el plazo prescriptivo, de conformidad con el art. 1969 CC, es de hechos y no de derechos, pues «es evidente que no forma parte del "material cognoscible" la norma o fuente del derecho, en general, en que se funde el derecho del reclamante. Esto es casi obvio, porque la ignorancia del derecho es un riesgo de quien lo padece. Es claro que si el actor no sabe que dispone de una acción en caso de contrato nulo o no sabe que el plazo de prescripción es uno determinado, este riesgo no lo puede desplazar al legitimado pasivo de la acción mediante un retraso en el dies a quo del plazo de prescripción. Aunque el desconocimiento sea excusable en términos de conducta negligente. Por tanto, el riesgo del derecho y su interpretación es un riesgo propio del actor, con el que no se puede manipular el inicio del plazo de prescripción de la acción de que se trata. Cualquier prestatario pudo reclamar la nulidad/restitución de la cláusula de gastos, y si era nula el 23 de diciembre de 2015, también lo era antes».

Ahora bien, ¿qué establece la reciente STJUE de 16 de julio de $2020^{40}$ con respecto al dies a quo del plazo de prescripción de la acción restitutoria? Reproduzco los apartados 88, 89, 90, 91 y 92 de la Sentencia:

«88. El órgano jurisdiccional remitente alberga también dudas, en esencia, acerca de si es compatible con el principio de efectividad, en relación con el principio de seguridad jurídica, una jurisprudencia nacional con arreglo a la cual el plazo de prescripción de cinco años para el ejercicio de una acción dirigida a hacer valer los efectos restitutorios de la declaración de la nulidad de una cláusula contractual abusiva comienza a correr a partir de la celebración del contrato que contiene esta cláusula.

89. Del auto de remisión se desprende que este plazo, fijado en el artículo 1964, apartado 2, del Código civil, parece empezar a correr a partir de la conclusión de un contrato de préstamo hipotecario que contiene una cláusula abusiva, extremo este cuya comprobación, no obstante, corresponde al órgano jurisdiccional remitente.

\footnotetext{
37 RJ 2013\3088: «[C]onsecuentemente con lo expuesto, procede declarar la irretroactividad de la presente sentencia, de tal forma que la nulidad de las cláusulas no afectará a las situaciones definitivamente decididas por resoluciones judiciales con fuerza de cosa juzgada ni a los pagos ya efectuados en la fecha de publicación de esta sentencia» (FJ 17).

38 CARRASCO PERERA, A.: «A vueltas (y esperemos que la última) sobre el plazo de prescripción de la acción nacida de la nulidad de la cláusula de repercusión al prestatario de todos los gastos hipotecarios», Publicaciones jurídicas del Centro de Estudios de Consumo (CESCO), septiembre 2017, págs. 4 y ss. Disponible en: http://centrodeestudiosdeconsumo.com/images/Prescripcion clausula gastos hipotecarios.pdf

39 MARÍN LÓPEZ, M.J.: La nulidad de la cláusula de gastos en los préstamos hipotecarios, Colección Derecho del Consumo, Ed. Reus, Madrid, 2018, pág. 266.

40 TJUE (Sala Cuarta), Caso varios contra varios (C-224/19 y C-259/19), sentencia de 16 julio 2020 (TJCE 2020\104).
} 
90. A este respecto, procede tener en cuenta la circunstancia de que es posible que los consumidores ignoren que una cláusula incluida en un contrato de préstamo hipotecario sea abusiva o no perciban la amplitud de los derechos que les reconoce la Directiva 93/13 (véase, en este sentido, la sentencia de 13 de septiembre de 2018, Profi Credit Polska, C-176/17 (TJCE 2018, 208), EU:C:2018:711, apartado 69).

91. Pues bien, la aplicación de un plazo de prescripción de cinco años que comience a correr a partir de la celebración del contrato, en la medida en que tal aplicación implica que el consumidor solo pueda solicitar la restitución de los pagos realizados en ejecución de una cláusula contractual declarada abusiva durante los cinco primeros años siguientes a la firma del contrato - con independencia de si este tenía o podía razonablemente tener conocimiento del carácter abusivo de esta cláusula-, puede hacer excesivamente difícil el ejercicio de los derechos que la Directiva 93/13 confiere a este consumidor y, por lo tanto, vulnerar el principio de efectividad, en relación con el principio de seguridad jurídica.

92. Habida cuenta del conjunto de las anteriores consideraciones, debe responderse a la decimotercera cuestión prejudicial planteada en el asunto C224/19 que el artículo 6, apartado 1, y el artículo 7, apartado 1, de la Directiva 93/13 deben interpretarse en el sentido de que no se oponen a que el ejercicio de la acción dirigida a hacer valer los efectos restitutorios de la declaración de la nulidad de una cláusula contractual abusiva quede sometido a un plazo de prescripción, siempre que ni el momento en que ese plazo comienza a correr ni su duración hagan imposible en la práctica o excesivamente difícil el ejercicio del derecho del consumidor a solicitar tal restitución» (apartado que se reproduce posteriormente en el fallo).

AGÜERO ORTIZ ${ }^{41}$, apoyándose en los apartados 90 y 91 de la sentencia, sostiene que «cabe comprender que el TJUE introduce una novedad respecto a la jurisprudencia del TS, pues parece que no exige solo un conocimiento de los hechos, sino también del derecho a reclamar al requerir la toma en consideración del momento en que el consumidor pudo tener razonablemente conocimiento de la abusividad de la cláusula. De este modo, se da cabida a la interpretación de que el dies a quo de la acción ha de ser la fecha de publicación de la STS 23.12.2015, esto es, el 21.1.2016 para los préstamos suscritos con anterioridad a ella, y la fecha de recepción de las facturas en caso de préstamos suscritos con posterioridad» ${ }^{42}$.

\footnotetext{
${ }^{41}$ AGUËRO ORTIZ, A.: «Cláusula de gastos en la STJUE de 16.7.2020: ¿más gastos restituibles; extensión del plazo para instar la restitución y condena en costas si la cláusula se declara abusiva?», Publicaciones jurídicas del Centro de Estudios de Consumo (CESCO), julio 2020, pág. 16. Disponible en: http://centrodeestudiosdeconsumo.com/images/Clausula de gastos en la STJUE de 16.7.2020.pdf.

42 En contra, ACHÓN BRUÑÉN quien mantienen que, atendiendo a la reciente STJUE de 16 de julio de 2020 de la que se infiere que los efectos restitutorios derivan de la declaración de nulidad, es lógico que sea este momento el dies a quo del plazo de prescripción (en «Qué ha cambiado tras la Sentencia del TJUE de 16 de julio de 2020: gastos hipotecarios, comisión de apertura, prescripción de la acción y costas», Diario La Ley, núm. 9700, septiembre de 2020, pág. 11) No obstante, esto supondría que la posibilidad de solicitar la restitución de lo indebidamente abonado como consecuencia de una cláusula nula pueda
} 
No obstante, puede contrargumentarse que la STJUE de 16.07.2020 únicamente advierte que un plazo de prescripción de cinco años contados desde la celebración del contrato puede vulnerar el principio de efectividad, en relación con el principio de seguridad jurídica, pues es posible que en ese momento los consumidores ignoren que la cláusula es abusiva o no perciban la amplitud de los derechos que les reconoce la Directiva 93/13 (vid supra apdo. 91 de la sentencia). Es decir, el Tribunal de Luxemburgo examina en los apartados 89,90 y 91 si el plazo de cinco años que se computa desde la celebración del contrato es conforme al Derecho de la Unión supuesto que le plantea el órgano jurisdiccional remitente-.

Nada dice sobre cuándo debe fijarse el dies a quo para el cómputo del plazo de prescripción que el Derecho nacional establece para el ejercicio de la acción de restitución, sino que se limita a señalar que para no vulnerar los principios de efectividad y seguridad jurídica «ni el momento en que ese plazo comienza a correr ni su duración hagan imposible en la práctica o excesivamente difícil el ejercicio del derecho del consumidor a solicitar tal restitución» (vid supra apdo. 92 y fallo de la STJUE de 16.07.2020). Es pues, con arreglo a estos criterios $y$ no conforme a la teoría del conocimiento de la abusividad de la cláusula, como los tribunales nacionales deberán determinar cuándo debe situarse el día inicial del cómputo del plazo.

«No se puede "saltar" de una declaración tan vaga a la fijación predeterminada de un plazo de prescripción homogéneo en el orden nacional. Y es evidente que no puede valer una regla que establezca que el dies a quo del plazo comenzará según y cómo haya ocurrido cada caso. Porque cada uno conoce o no conoce no sólo a causa de sus condiciones subjetivas, sino también en función de su diligencia. Es notorio que un plazo de cinco años desde el momento del pago es un plazo suficiente. Desde luego lo es cuando en este plazo se ha ejercitado la acción de nulidad y se deja para más tarde la pretensión restitutoria. Pero lo es también en otro caso. Con el nivel de información existente en el ambiente y con la presión ejercida por los caza-pleitos de consumo, todo lo que hay que saber se sabe en cinco años. Otra cosa es que el consumidor no quiera correr el riesgo de pleitear hasta no encontrase totalmente seguro de su causa. Pero no es la función del Derecho de la prescripción neutralizar este riesgo ni garantizar que se apuesta sobre seguro» ${ }^{43}$.

Por todo ello, lo más acorde con el art. 1969 CC, en sus dos vertientes interpretativas, y con la doctrina de la STJUE de 16.07.2020, sería fijar el dies a quo en el momento en que se produce la condictio indebiti, es decir, desde que se realizaron los pagos indebidos, pues desde ese mismo momento la cláusula en virtud de la cual se efectúan los mismos ya es nula. Además, no es posible asumir la vinculación del nacimiento de una acción de reclamación de cantidad a una sentencia del Tribunal Supremo, máxime si tenemos en cuenta que en la STS de 23 de diciembre de 2015 se fija la nulidad de la cláusula y en las SSTS de Pleno de 23 de enero 2019 se fijan los efectos derivados de tal nulidad -y ello con casi cuatro años de diferencia-. Incluso

mantenerse sine die. Vid ÁLVAREZ ROYO-VILLANOVA, S.: «Gastos de hipoteca y comisión de apertura: novedades en la STJUE de 16 de julio de 2020», Revista El Notario del Siglo XXI, núm. 94/2020.

43 CARRASCO PERERA, Working Paper CESCO, 2020/6 
existen gastos, como los de tasación del inmueble, sobre los que aún no se ha resuelto.

Por último, señalar que si el dies a quo fuera la fecha de publicación de la STS de 23 de diciembre de 2015, la fecha fine del plazo de prescripción no sería, tal y como ha advertido recientemente el Ministerio de Consumo a través de redes sociales ${ }^{44}$, el 21 de enero de 2021, pues los plazos de prescripción quedaron suspendidos como consecuencia de la declaración del Estado de Alarma.

En este sentido, la Disposición Adicional Cuarta del RD 463/2020 de 14 de marzo ${ }^{45}$ estableció que «[I]os plazos de prescripción y caducidad de cualesquiera acciones y derechos quedarán suspendidos durante el plazo de vigencia del estado de alarma $y$, en su caso, de las prórrogas que se adoptaren», señalando posteriormente el art. 10 del RD 537/2020 de 22 de mayo ${ }^{46}$ que «[c]on efectos desde el 4 de junio de 2020, se alzará la suspensión de los plazos de prescripción y caducidad de derechos y acciones».

Por consiguiente, si las acciones de restitución nacieron, según el Ministerio de Consumo, el 21 de enero de 2016 -después de la entrada en vigor de la Ley 42/2015 de 5 de octubre ${ }^{47}$-, estas prescribirán, no el 21 de enero de 2021, sino el próximo 13 de abril de 2021, pues los plazos de prescripción quedaron suspendidos durante 82 días -desde el 14 de marzo hasta el 3 de junio del 2020-48.

\section{Bibliografía}

ACHÓN BRUÑÉN, M.J.: «Qué ha cambiado tras la Sentencia del TJUE de 16 de julio de 2020: gastos hipotecarios, comisión de apertura, prescripción de la acción y costas», Diario La Ley, núm. 9700, septiembre de 2020.

AGUËRO ORTIZ, A.: «Cláusula de gastos en la STJUE de 16.7.2020: ¿más gastos restituibles; extensión del plazo para instar la restitución y condena en costas si la cláusula se declara abusiva?», Publicaciones jurídicas del Centro de Estudios de Consumo (CESCO), julio 2020. Disponible en:

\footnotetext{
44 «El plazo de reclamación de la devolución de los gastos acaba el 21 de enero de 2021 en la mayoría de los casos», 9 de enero de 2021.

45 Real Decreto 463/2020, de 14 de marzo, por el que se declara el estado de alarma para la gestión de la situación de crisis sanitaria ocasionada por el COVID-19 («BOE» núm. 67, de 14/03/2020).

46 Real Decreto 537/2020, de 22 de mayo, por el que se prorroga el estado de alarma declarado por el Real Decreto 463/2020, de 14 de marzo, por el que se declara el estado de alarma para la gestión de la situación de crisis sanitaria ocasionada por el COVID-19 («BOE» núm. 145, de 23/05/2020).

47 Ley 42/2015, de 5 de octubre, de reforma de la Ley 1/2000, de 7 de enero, de Enjuiciamiento Civil («BOE» núm. 239, de 6 de octubre de 2015).

48 AGÜERO ORTIZ, A. y MARÍN LÓPEZ, M.J.: «Una vez alzada la suspensión de los plazos sustantivos de prescripción y caducidad ¿se reinician o se reanudan a partir del 4 de junio? ¿Qué fórmula sería la adecuada para calcular el cómputo?» en BERLOTÁ NAVARRO, I. y LÓPEZ-DÁVILA AGÜEROS, F. (Coord.), Encuesta Jurídica, Editorial Jurídica Sepín, junio de 2020. Disponible en: https://www.zsasociados.com/wpcontent/uploads/2020/06/Documento-SEPIN-SP DOCT 106637.pdf (Consultado: 11/01/2021)
} 
http://centrodeestudiosdeconsumo.com/images/Clausula de gastos en la STJUE de 16.7.2020.pdf.

AGÜERO ORTIZ, A.; MENDOZA LOSANA, A.I. y PARRA MEMBRILLA, L.: «Protección del consumidor-deudor hipotecario: realidad y perspectivas de futuro. Acta del Curso de Verano, Cuenca 3 y 4 de julio de 2017», Revista CESCO De Derecho De Consumo, núm. 22/2017, págs. 1-43.

AGÜERO ORTIZ, A. y MARÍN LÓPEZ, M.J.: «Una vez alzada la suspensión de los plazos sustantivos de prescripción y caducidad ¿se reinician o se reanudan a partir del 4 de junio? ¿Qué fórmula sería la adecuada para calcular el cómputo?» en BERLOTÁ NAVARRO, I. y LÓPEZ-DÁVILA AGÜEROS, F. (Coord.), Encuesta Jurídica, Editorial Jurídica Sepín, junio de 2020. Disponible en: https://www.zsasociados.com/wpcontent/uploads/2020/06/Documento-SEPIN-SP DOCT 106637.pdf

ÁLVAREZ ROYO-VILLANOVA, S.: «Gastos de hipoteca y comisión de apertura: novedades en la STJUE de 16 de julio de 2020», Revista El Notario del Siglo XXI, núm. 94/2020.

CAÑIZARES LASO, A.: «Algunas claves para la reforma de la prescripción. En especial el dies a quo», Revista de Derecho Civil, Vol. V, núm. 4/2018, págs. 89-138.

CARRASCO PERERA, A.: «A vueltas ( $y$ esperemos que la última) sobre el plazo de prescripción de la acción nacida de la nulidad de la cláusula de repercusión al prestatario de todos los gastos hipotecarios», Publicaciones jurídicas del Centro de Estudios de Consumo (CESCO), septiembre 2017. Disponible en: http://centrodeestudiosdeconsumo.com/images/Prescripcion clausula gastos hipot ecarios.pdf

CARRASCO PERERA, A.: «La acción para reclamar intereses pagados en virtud de una cláusula suelo está prescrita cuando han transcurrido cuatro años desde que el contrato hipotecario ha sido consumado y cancelado», Revista CESCO de Derecho de Consumo, núm. 21/2017, págs. 90-105.

DÍEZ-PICAZO Y PONCE DE LEÓN, L.: «Presupuestos de ejercicio de la facultad de prescripción», La prescripción extintiva en el Código civil y en la jurisprudencia del Tribunal Supremo, 2.a ed., Ed. Cívitas, Madrid, 2007. http://aranzadi.aranzadidigital.es.

DOMÍNGUEZ MARTÍNEZ, P.: «Comentario al art. 1969 del CC», en BERCOVITZ RODRÍGUEZ-CANO, R. (Coord.), Comentarios al Código Civil, 3.a ed., Ed. Aranzadi, Navarra, 2009. http://aranzadi.aranzadidigital.es.

MARÍN LÓPEZ, M.J.: «La prescripción de la acción de nulidad de la cláusula de gastos y de la acción de restitución de los gastos abonados», Revista CESCO de Derecho de Consumo, núm. 22/2017, págs. 86-99.

MARÍN LÓPEZ, M.J.: La nulidad de la cláusula de gastos en los préstamos hipotecarios, Colección Derecho del Consumo, Ed. Reus, Madrid, 2018. 
MIQUEL GONZÁLEZ, J.M.: «La acción de nulidad no es una acción porque no entraña una pretensión», Almacén de Derecho, 2017. Disponible en: https://almacendederecho.org/la-accion-nulidad-no-una-accion-no-entrana-unapretension

PEÑA LÓPEZ, F.: «El dies a quo y el plazo de prescripción de las acciones de responsabilidad por daños en el CC: criterios procedentes de algunos textos europeos de soft law y del Derecho estadounidense que podrían servir para su reforma e interpretación», InDret, núm. 4/2011, págs. 2-26. 